\title{
Research Artick: Adoption of dry land crop (Pearl millet) production technology by the farmers in Barmer district
}

\author{
Pradeep Pagaria, S.L. Kantwa and Shyam Das
}

Article Chronicle:

Received :

25.04.2017;

Revised :

01.01.2018;

Accepted :

17.01.2018

SUMMARY : The present study was conducted in Chohtan and Sedva tehsil from Barmer district, six village from each tehsil were selected randomly and from each village fifteen Bajra growers were selected. Thus a sample of 180 respondents was made. Majority of respondents (50\%) had medium adoption level regarding dryland crop production technology. The personal and socio-economic characterstics such as education, land holding, annual income, sources of information and economic motivation had positive and significant relationship with adoption of dryland crop production technology. The major constraints regarding adoption of dryland crop production technology were higher seed cost, scientific method of cultivation, non availability of seeds at proper time, non availability of plant protection appliances, lack of knowledge of plant protection etc.

How to cite this article : Pagaria, Pradeep, Kantwa, S.L. and Das, Shyam (2018). Adoption of dry land crop (Pearl millet) production technology by the farmers in Barmer district. Agric. Update, 13(1): 81-83; DOI : 10.15740/HAS/AU/13.1/81-83.

Key Words:

Dryland crop, Pearl

millet, Product

technology

Author for correspondence : 